\title{
A Comprehensive Look at Multi-Age Education
}

\author{
Nadeem Saqlain \\ Memorial University of Newfoundland, Canada \\ Email: nadeems@mun.ca
}

\section{Doi:10.5901/jesr.2015.v5n2p285}

\begin{abstract}
Multi-grade schooling has been used in many countries around the globe. It is a cost effective model of schooling especially in rural areas where teacher retention and recruitment is a major problem. The findings of various research studies indicate that multi-grade education is as effective as single-grade schooling in terms of academic achievement and better in terms of social learning. The success of multiage education greatly depends on teaching techniques. Our universities prepare teachers for single-grades. Therefore, teachers in multi-grade settings face many challenges such as inadequate training, social and cultural isolation, instructional, lack of time, lack of community understanding, and rural nature of most of the multi-grade settings. Some of the issues can be overcome through proper pre-service and in-service teacher training.
\end{abstract}

Keywords: Multi-grade, multi-age, rural education, social learning, group learning.

\section{Introduction}

Multi-age classrooms are common in some parts of the world. However, multi-age education has not been getting enough attention of educators, parents, and policy makers. One of the main reason is the lack of understanding of multiage education. The main objective of this article is to enhance readers' understanding towards multi-age education. The paper may be beneficial for rural educators, researchers and policy makers. A judicious use of multi-age education can augment learners' achievements. In this article, first, I will look at the history of multi-age education, and then, I will explore the effectiveness of multiage education. Finally, I will shed light on the challenges of multi-age education. One of the limitations of the paper is that it is not a research study. It is based on my arguments with the support of previous published literature in the field of multi-age education.

In multi-grade settings, a teacher has to perform pedagogical responsibilities for more than one class in one classroom. In the early 1900's Horace Mann introduced multi-grade classes in the United States (Aina, 2001). The multigrade class concept developed due to a shortage of teachers in rural areas (Sag, Savas \& Sezer, 2009). Today, multi$\mathrm{grad} / \mathrm{multi}$-age classes are common around the globe due to: administrative necessity, declining enrolment, or a pedagogical choice (Mulcahy, 1992). Little (2006) depicted the picture of multi-age education by reporting its presence in England, India, Northern Ireland, Peru, and Sri Lanka had multi-age classes. Multi-age classes are also common in the US, Canada, Europe, Australia, New Zealand and some parts of Asia. Cornish (2009) defines multi-age education and states that sometimes students are grouped by choice. This type of grouping is called multi-age. Mainly, multi-grade classes are rural while multi-age classes are urban. Several terms are used for multi-grade/multi-age education such as family grouping, blends, non-graded (Joan, 1997), composite classes and combined classes.

Multi-age education is an economical way to educate students from less populated areas (Ritland \& Eighmy, 2013). Multi-age education is child entered education instead of curriculum centered (Stone, 2004). Students' individual needs and different learning styles are given preferences. Multi-age setting is a natural environment for the learners (Aina, 2001). They are in a community of intellectuals where they learn from each other. They are tutors, tutees, peers, friends and role models at the same time. They help, teach and guide each other. Multi-age schooling has been used in some settings due to the benefits of peer tutoring and independent inquiry (Thomas \& Shaw, 1992). According to Little (2001), multi-age education is widespread, but it is overlooked by many researchers, teachers, parents and policy makers. Little states that the knowledge of multi-age education is invisible in text books, teacher guides, teacher training colleges, and in teaching methods. As a result, many education systems across the globe are organised according to mono-grade schooling (Pridemore, 2007). Aina (2001) describes that some parents and students do have apprehensions of learning in multi-age schooling. The parents are curious to know the effectiveness of multiage education. The focus of this paper is also to illustrate the effectiveness of multi-age education in order to eradicate the apprehensions and 
concerns of multi-age education.

\section{Students Learning}

The effectiveness of multi-grade education has been supported by the findings of many studies. Numerous research studies have been conducted since 1960s on cognitive and non-cognitive outcomes of multi-age learners (Hoffman, 2007). The main purpose of the review was to explore the effects of multi-grade and mono-grade education on students' learning outcomes. Pratt (1986) reviewed 30 research studies conducted between 1948 and 1983 in the North America. Some researchers reported high cognitive achievements for the students in multi-grade classes and some reported for single grade classes. Most of the researchers reported no difference in terms of students learning outcomes. However, in terms of non-cognitive achievements such as building friendships, improving self esteem, self concept and social development, the findings favored multi-grade education.

Miller (1991) undertook a review of 21 educational studies from the USA. The findings indicated that the students in multi-grade classes performed as well as the students in mono-grade classes. Multi-grade students performed better in comparison to their mono-grade counterparts on non-cognitive achievements. Veenman (1995) reviewed 38 research studies from around the world. The researcher found no difference in learning between multi-age classes and single age classes. The findings indicated effects on students' attitudes toward self esteem and self concept favoring multi-age classes. Corrigan, Hemmings and Kay (2007) conducted a research study with seventy-three students and five teachers from an elementary school. The authors reported that single-age versus multi-age class types had no significant effect on the overall literacy achievements of junior kindergarten children.

Multi-age education is effective because students' strengths are emphasized instead of their weaknesses and students feel less competition (Aina, 2001; Banks, 1997). Multi-age schooling recognises that each learner is different by focusing on the developmental stage of learners. Diversity is embraced and students are provided opportunities to gain knowledge through interaction with each other. Multi-age schooling motivates students by providing them a lot of activities according to their learning styles, learning abilities, intelligences and interests (Banks, 1997). According to Gaustad (1997), group learning increase social skills and decrease antisocial behavior. Ritland and Eighmy (2013) undertook a quantitative research study with 21 multi-age experts. Data were collected through Delphi methodology using three rounds of surveys of written questions and statements. Delphi methodology is used to gather data from experts in the field. The findings of the study showed that the participants were quite optimistic about the effectiveness of multi-age education in the present era. The participants acknowledged that the learners of all abilities and needs could benefit in a multi-age setting. The participants also agreed that all the stakeholders including parents, teachers, school boards, principals and superintendents should have training on the philosophy and strategies of multiage education. This was the first study of its nature, in which, multi-age schooling experts participated. Benveniste and McEwan (2000) argue that multi-age schools can be cost effective in developing countries to promote equity in education especially in rural areas. These schools can be beneficial for many disadvantaged and marginalised young children and girls (Pridmore, 2007). For example, the retention and recruitment of females teachers in rural Pakistan is a serious issue (Shaukat, 2009). This issue can be overcome with the implementation of multi-age education by recruiting less teachers.

\section{Social Learning}

The educational research is very clear about the social development of learners in multi-age settings. Most studies (Colbert, Chiappe \& Arboleda, 1993; Psacharopoulos, Rojas \& Velez, 1993) presented the evidence that students in multi-grade schooling learned social skills better than their counterparts in mono-grade schooling. The concepts of collaborative learning and peer tutoring are deep rooted in Vygotsky's (1978) social constructive theories which show that learners construct their own knowledge and learn through shared experiences with others. In multi-age classes, children learn through cooperative learning, peer tutoring and observation (Bank, 1997). This interaction is two ways; junior learn from seniors and seniors learn from juniors through interactions. Miller (1991) presents an example of kindergarten students who first time, while entering to school, receive help and guidance not only from their teachers but also from older students. Maeda (1994) described few characteristics of multi-age classes such as maximum learning opportunities in a natural environment, teaching consistent with different learning styles, teaching according to the social, emotional and intellectual development of the learners, learning through interaction with peers and with teachers, and independent learning. 


\section{Teaching Methodology}

The success of the multi-age education depends upon the implementation of successful teaching techniques. The successful teaching is possible through adequate learning material to support individual and group-based learning (Little, 2005). Bandy (1980) surveyed 500 teachers and 50 principal from British Columbia, Canada. The data were also collected through interview from 32 participants. One of the participants indicated that a teacher's ability to plan and organise was the most important factor in multi-age education. According to Thomas and Shaw (1992), multi-age teachers must know a variety of teaching techniques, they must have enough teaching and learning material and be supported by the local and national communities. They conclude that an effective teaching methodology which includes careful lesson planning, peer tutoring, self directed learning, creation of a conducive learning environment, and frequent assessment and feedback can help learners for higher achievements. Gaustad (1995) also adds that a multi-age teacher should have in depth knowledge of learners' development and learning styles.

Miller $(1991$, p.10,11) identified six key factors affecting successful teaching in multi-age education:

1. Class organisation

2. Class management and discipline

3. Instructional organisation and curriculum

4. Instructional delivery and grouping

5. Self directed learning

6. Peer tutoring

The success of multi-grade schooling heavily depends on various factors such as time for teaching, planning and organisation (Gaustad, 1992). Hoffman (2003) carried out a qualitative research study in a multi-age setting and data were collected from four teachers through interviews and classroom observations. The findings showed four categories of beliefs e.g. differentiated instruction, social collaboration, flexible grouping and student interest. The participants had some common beliefs such as the need of acquaintance with each other. The teacher should know the students and their individual characteristics. The teacher should facilitate learning through opening different avenues for the learners. The students should be grouped flexibly throughout the day. Teacher should plan activities consistent with the needs of the learners by recognizing different learning styles. Students should have opportunities to make choices in curriculum. Diversity should be accommodated. Ritland and Eighmy (2013) also recommended a few strategies such as differentiated instruction, learning project areas, inquiry-based learning and thematic instruction to use in multi-grade settings. The learners who learn to work independently can work on learning project areas which address a variety of interests and abilities. Inquiry based learning and thematic learning can also be used in multiage schools. Teachers allow students to research real life issues of their interests and work on them such as the learners can work on a project in a group. The learners have multiple roles such as a manager, a reporter, an assistant. They also explore the issue from diverse angles such as historical, scientific and technological. Aina (2001) describes a successful implementation of multi-grade schooling needs time management and planning, flexibility, practical teacher training and ongoing communication plan.

\section{Challenges to Multi-grade Teaching}

Multi-grade education is widespread in rural areas in many countries such as Sri Lanka, Nepal, and England. Therefore, many challenges such as social isolation, inadequate professional development and lack of facilities of a multi-grade teacher are similar to the challenges of a rural teacher (Aksoy, 2008). Teaching multi-grade classes in not an easy task. Some authors report that multi-grade teaching is more difficult than the mono-grade teaching (Mason\& Burns, 1995). The problems at multi-grade classes are not just a single nature but they are myriad and varied in nature such as administrative, political and geographical. Sag, Savas and Sezer (2009) surveyed 38 multi-age teachers. They found that teachers at multi-grade classes faced multiple types of challenges including school administration, instructional programs, assessment and evaluation and socio economic environment. They suggested in-service teacher training for multi-grade teaching a solution of some of the issues. They also suggested that school administration, instructional programs, instructional conditions and assessment should be part of the in-service teacher training program. Similarly, Aksoy (2008) highlighted challenges to multi-grade teachers such as political, geographical, economical, social and cultural barriers such as teachers in Turkey are not interested in teaching in poor regions. He concluded that in Turkey, poverty and the rural nature of the regions of multi-grade schools were the main causes of these problems. Birch and Lally (1995) go further and mention some more obstacles to multi-grade teaching e.g. inattentiveness of education 
officers, lack of financial incentives for multi-grade teachers, inadequate housing and employment opportunities for teachers' spouses, and lack of educational opportunities for teachers' children and absence of promotional incentives.

\section{Inadequate Teacher Training}

Most of the teachers who teach at multi-grade levels are young and inexperienced. Some of them receive very little preservice or in-service teacher training (Sag, 2009). Especially, novice teachers with no multi-grade teaching training are reluctant to take responsibilities in multi-grade settings. Teachers' perceptions on multi-grade teaching are significant to understand the challenges of multi-grade teaching. Some of the teachers perceptions were highlighted in various studies such as Suzuki (2004) conducted a research study in Nepal with 50 multi-grade teachers. The data were collected through observations, interviews, documents, questionnaires and focussed group discussions. The findings indicated that multi-grade teaching was more challenging than teaching in single-grade class. The findings also indicated that multigrade teachers receive little support due to predominance of mono-grade teaching. This also a proof of policy makers' inattentiveness to multi-age schooling.

Inadequate professional training for pre-service teachers at university level is one of the preliminary challenges of teaching multi-grade classes. In one of their studies, Izci, Duran and Tasar (2010) collected data through questionnaires from 82 primary school teachers working in multi-grade classes and 185 pre-service teachers in Turkey. All the participants lamented on the lack of teacher training at university level to teach multi-grade classes. However, all the participants emphasized the significance of multi-grade education. It can be concluded that multi-age schooling is significant, therefore, universities should pay special attention towards multi-age teacher preparation programs. In order to know the perceptions of pre-service teachers, Sag (2009) carried out a qualitative research by interviewing participants and he found that the first challenge to teach multi-grade classes began with teacher training where universities were providing inadequate training to teach multi-age or multi-grade classes. In most countries, pre-service teachers are prepared for mono-grade classes (Aksoy, 2008). As a result, less attention is given to multi-age teacher preparation.

\section{Lack of Time for Teaching and Planning}

Most teachers believe that multi-grade teaching requires more time than mono-grade teaching (Pratt \& Treacy, 1996). Kyne (2004) conducted a research study with 75 multi-age teachers and found that $70 \%$ percent teachers were concerned about the lack of time for teaching. The findings also indicated some other challenges such as inadequate text books, teacher preparation, lack of space, large class sizes and lack of support. In a mono-grade setting, a teacher prepares one lesson for all the students in a class. However, in a multi-grade setting a teacher has to prepare a lesson for multiple grades which consumes more out-of-class time. A lack of time for teaching, planning and organisation is one of the major issues in multi-age/multigrade education (Joan, 1992). Teachers need time to group and regroup students for pedagogical purposes (Chapman, 1995). In rural settings, multi-grade teachers have to perform other responsibilities as well such as being on committees, participating in meetings and hosting/leading extra-curricular activities. All these activities eat up a major portion of teachers' preparation time.

\section{Prescribed Curriculum \& Assessment}

In order to respond to students' needs, a multi-age teacher needs to move beyond the standardized curriculum (Aina, 2001). In reality, multi-grade teachers are unable to design a curriculum for multi-grade teaching. As a result, they have to teach mono-grade curriculum. The standard curriculum is designed for the needs of mono-grade settings. Teaching mono-grade curriculum in multi-grade classes is an exhausting task for multi-age and multi-grade teachers who have to cover all the curriculum in a limited span of time because they are responsible for more than one grade (Mulcahy, 1991). Multi-age teachers teach students of various ages and maturity levels but the teachers do not have multi-age education curriculum. They have to follow the single grade curriculum. Teaching single-grade's curriculum to diverse learners is also an arduous task. The teachers face, further, challenges such as how to engage everyone or how to deal with knowledge gap to implement the standard curriculum. The situation becomes worse in developing countries where it is considered one of the main challenges of multi-grade teachers to go beyond the curriculum or to make adjustment according to the needs of the learners (Cornish, 2009).

Similarly, multi-grade student assessment creates another problem. The prevalent assessment system is designed for mono-grade classes (Hargreaves, 2001). Therefore, multi-grade teachers have to use the methods of assessment 
and evaluation which are prescribed for single grade classes to evaluate students' different levels of learning in multigrade settings.

\section{Lack of Community Understanding}

Research has shown that multi-grade teachers receive very little support from the administrative staff, from the parents and from the local community where the multiage schools exist. Joan (1997) states that parents and community support has positive effect on students' learning. He emphasises the need for parental support, the local educational community support and the support of general public for multi-age education to be successful. Teachers' problems enhance due to lack of community support. Aina (2001) writes that parents and students are really concerned about the multi-age education program. Parents are dubious regarding the success of the multiage program. Therefore, community understanding and support is integral to the success of multi-age classes.

\section{Rural Schools}

Rural communities around the globe have a constant problem of shortage of teachers (Barbour, 2007). Therefore, multigrade class settings are usually situated in small rural areas (Kyne, 2004). In some cases, a teacher has to perform multiple roles such as a principal, a teacher, a student counsellor, a clerk, a bus driver and a caretaker. Teachers have to travel from other communities. Aksoy (2008) reports that more than $50 \%$ multi-grade teachers have to commute to schools from urban or suburban communities. Moreover, because of the rural nature of the regions, most of the teachers consider rural teaching a sort of forced exile. Therefore, many rural teachers' first preference is to get transferred to close to their homes. Many rural schools have poor infrastructure with inadequate materials for teaching and learning. Closure and consolidation of small schools is another barrier to attract and retain qualified teachers especially those who are interested in multi-grade teaching. In some cases, many teacher vacancies remain unfilled which increase burden on other teachers in the school. Moreover, rural schools in developing countries receive a little attention from the officials. As a result, students have lack of text books, and teachers find inadequate space for grouping and regrouping of students in classes.

\section{Conclusion}

Multi-age education is common around the globe but it has less attention from policy makers, educators and parents. Most multi-grade settings are in rural areas. However, some teachers from urban areas also group students for pedagogical choices. The review of the previous studies indicated that students in multi-age settings learn social skills better than those who are in mono-grade settings. Of course, the implementation of multi-age schooling can play a major role in the equitable educational delivery in rural areas. To make multi-age schooling successful, the involvement of parents, educators, policy makers and local educational community is very important. Multi-age education is cost effective and one of the best solutions of shortage of teachers in remote areas. The success of multiage education heavily depends on the proper implementation of the program through teacher training, the provision of learning material and community support. Therefore, there is an immense need of community understanding and involvement. In spite of the fact that there are divers challenges to multi-age education, it is not impossible.

\section{Acknowledgements}

I would like to express my very great appreciation to Dr. Dennis Mulcahy for his valuable suggestions with this paper.

\section{References}

Aina, O., E. (2001). Maximizing learning in early childhood multi-age classrooms: Child, teacher, and parent perceptions. Early Childhood Education Journal, 28(4), 219-224.

Aksoy, N. (2008). Multi-grade schooling in Turkey: An overview. International Journal of Educational Development, 28, 218-228.

Bandy, J. \& Gleadow, N. (1980). The identification of skills and characteristics needed by country school teacher. Victoria, BC: University of Victoria.

Banks, J. C. (1997). Student success, and self image in a multi-age classroom. Retrieved from http://www.multi-age-education.com/ mult-iagen-b/stsuccess.html 
Barbour, M. K. (2007). Portrait of rural virtual schooling. Canadian Journal of Educational administration and Policy, 59,1-21.

Benveniste, L. A., \& McEwan, P. J. (2000). Constraints to implementing educational innovations: The case of multigrade schools. International Review of Education, 46(1-2), 31-48.

Birch, I and Lally, M. (1995) Multigrade Teaching in Primary Schools, Asia-Pacific Centre of Education Innovation for Development, Bangkok.

Chapman, M. L. (1995). Designing literacy learning experiences in a multi-age classroom. Language Arts, 72(6), $416-427$.

Colbert, V., Chiappe, C., \& Arboleda, J. (1993), 'The New School Program: More and Better Primary Education for Children in Rural Areas in Colombia', in Levin, H.M. \& Lockheed, M.E. Effective Schools in Developing Countries, London, Falmer Press.

Cornish, L. (2009). Teaching the world's children: Theory and practice in mixed-grade classes. International Symposium for Innovation in Rural Education, 117-126.

Corrigan, K. F., Hemmings, B., \& Kay, R. (2007). Single-age and multi-age groupings in kindergarten and their effect on literacy achievement. In Annual Conference of the Australian Association for Research in Education. Adelaide, South Australia.

Gaustad, J. (1995). Implementing the multi-age classroom. Retrieved from https://scholarsbank.uoregon.edu/xmlui/bitstream/handle/ 1794/3318/digest097.pdf?sequence=1

Gaustad, J. (1997). Building support for multi-age education. Retrieved from https://scholarsbank.uoregon.edu/xmlui/bitstream/ handle/1794/3336/digest114.pdf?seque nce=1

Hargreaves, E. (2001). Assessment for learning in the multigrade classroom. International Journal of Educational Development, 21(2001), 553-560.

Hoffman, J. (2003). Multi-age teachers' beliefs and practices. Journal of Research in Childhood Education, 18(1), 5-17.

Izci, E., Duran, H., \& Tasar, H. (2010). An investigation in multigrade class teaching with respect to primary school teacher candidates' perceptions and in views of primary school teachers working in multigrade classes. Ahi Evran Universitesi Egitim Fakultesi Dergesi, 11(1), 19-35.

Joan, G. (1992). Non graded primary education. Eric Digest, 74.

Joan, G. (1997). Building support for multi-age education. Eric Digest, 114

Kyne, M. C. (2004). Teaching and learning in multi-grade classrooms: What teachers say. The Irish Journal of Education, 35, 5-19.

Kyne, M. C. (2007). The preparation of teachers for multi-grade teaching. Teaching and Teacher Education, 23, 201-514.

Little, A. W. (2001). Multigrade teaching: towards an international research and policy agenda. International Journal of Educational Development, 21(6), 481-497.

Little, A. W. (2005). Learning and teaching in multigrade settings. Background paper for UNESCO (2005) EFA Global Monitoring Report. Maeda, B. (1994). The multi-age classroom: An inside look at one community of learners. Los Angeles, CA: Creative Teaching Press.

Mason, D. A., \& Burns, R. B. (1995). Teachers' views of combination classes. The Journal of Education, 89(1), 36-45.

Miller, B.A. (1991). A review of the qualitative research on multigrade education. Journal of Research in Rural Education 7 (2), 3-12.

Mulcahy, D. (1991). The Curricular challenge of Multi-age Groupings. Morning Watch.

Mulcahy, D. (1992). Do we still have multi-grade classrooms? Morning Watch, 20 (1/2), 1-7.

Pratt, D.(1986). On the merits of multiage classrooms. Research in Rural Education 3 (3), 111- 115.

Pratt, C., \& Treacy,K . (1986). A study of student grouping practices in early childhood classes in Western Australia government primary schools. (Cooperative Research Series, No.9). Perth, Australia: Education Department of Western Australia.

Pridmore, P. (2007). Adapting the primary-school curriculum for multi-grade classes in developing countries: a five-step plan and an agenda for change. Journal of Curriculum Studies, 39(5), 559-576.

Psacharopoulos, G. Rojas, C., \& Velez, E. (1993), 'Achievement Evaluation of Colombia's Escuela Nueva: Is Multigrade the Answer?', Comparative Education Review, 37(3), 263-276.

Ritland, V., \& Eighmy, M. (2013). Multi-age Instruction: An Outdated Strategy, or a Timeless Best Practice. The European Journal of Social \& Behavioural Sciences.

Sag, R. (2009). Becoming a teacher in multigrade classes. Electronic Journal of Social Sciences, 8 (28), 20-39.

Sag, R., Savas, B., \& Sezer, R. (2009). Characteristics, problems and needs of multigrade class teachers in Burdur. Inonu University Journal of the Faculty of Education, 10(1), 37-56.

Shaukat, A. (2009). Delivering girls' education in Pakistan. Retrieved from http://www.ungei.org/resources/files/delivering-educationpakistan-ukfiet09.pdf

Stone, S. (2004). Creating the multi-age classroom. Glenview, IL: Good Year Books.

Thomas, C., Shaw, C. P., \& Mundial, B. (1992). Issues in the development of multigrade schools (Vol. 172). Washington, DC: World Bank.

Suzuki, T. (2004) Multi-grade teaching in primary schools in Nepal: practice and training, (Unpublished doctoral dissertation), University of London, London.

Veenman, S., 1995. Cognitive and noncognitive effects of multigrade and multi-age classes: a best evidence synthesis. Review of Education Research 65 (4), 319-381.

Vygotsky, L. S. (1978). Mind and Society: The Development of Higher Psychological Processes (Cambridge, MA: Harvard University Press). 